\title{
Neutral Metalloproteinases Produced by Human Mononuclear Phagocytes Enzyme Profile, Regulation, and Expression during Cellular Development
}

\author{
Howard G. Welgus, * Edward J. Campbell,‡ James D. Cury,‡ Arthur Z. Eisen,” \\ Robert M. Senior, ${ }^{\ddagger}$ Scott M. Wilhelm, ${ }^{5}$ and Gregory I. Goldberg \\ Divisions of Dermatology, ${ }^{*}$ and Respiratory and Critical Care, ${ }^{\ddagger}$ Department of Medicine, Jewish Hospital at \\ Washington University Medical Center, and the Division of Dermatology, ${ }^{\S}$ Department of Medicine, \\ Washington University School of Medicine, St. Louis, Missouri 63110
}

\begin{abstract}
Mononuclear phagocytes are developmentally and functionally complex cells that play critical roles in extracellular matrix remodeling. We hypothesized that differentiated mononuclear phagocytes, typified by alveolar macrophages, use a spectrum of metalloproteinases to degrade various matrix macromolecules. To test this hypothesis, we have evaluated synthesis and secretion of four metalloproteinases (interstitial collagenase, stromelysin, 72-kD type IV collagenase, and 92-kD type IV collagenase) by human mononuclear phagocytes with regard to (a) the effect of cellular differentiation, (b) regulation of secretion, and (c) comparisons/contrasts with a prototype metalloproteinase-secretory cell, the human fibroblast. We found that regulated secretion of greater quantities and a wider spectrum of metalloenzymes correlated with a more differentiated cellular phenotype. As extreme examples, the 92-kD type IV collagenase was released by peripheral blood monocytes and uninduced U937 monocyte-like cells, whereas stromelysin was secreted only by lipopolysaccharide-stimulated alveolar macrophages. Macrophage production of interstitial collagenase, stromelysin, and 72-kD type IV collagenase was approximately $20 \%, 10 \%$, and $1-2 \%$, respectively, of that from equal numbers of fibroblasts; secretion of the 92-kD type IV collagenase was not shared by fibroblasts. This work confirms the potential of macrophages to directly degrade extracellular matrix via secreted metalloproteinases in a manner that differs both qualitatively and quantitatively from that of fibroblasts. Moreover, varying regulation of metalloenzyme synthesis, evidenced by distinct patterns of basal and stimulated secretion during differentiation, can be studied at a molecular level in this model system. (J. Clin. Invest. 1990. 86:1496-1502.) Key words: collagenase $\bullet$ differentiation $\bullet$ macrophages $\bullet$ metalloproteinases $\bullet$ monocytes
\end{abstract}

\section{Introduction}

Mononuclear phagocytes subserve a variety of immunoregulatory, phagocytic, and secretory functions. They play a pivo-

Dr. Campbell's present address is Division of Respiratory, Critical Care and Occupational Pulmonary Medicine, Department of Medicine, University of Utah Health Sciences Center, Salt Lake City, UT 84132.

Address reprint requests to Dr. Welgus, Division of Dermatology, Jewish Hospital at Washington University Medical Center, 216 South Kingshighway Boulevard, St. Louis, MO 63110.

Received for publication 24 October 1989 and in revised form 8 June 1990.

J. Clin. Invest.

(c) The American Society for Clinical Investigation, Inc.

0021-9738/90/11/1496/07 \$2.00

Volume 86, November 1990, 1496-1502 tal role in modulating the turnover of extracellular matrix (ECM), ${ }^{1}$ both directly by the secretion of proteinases and proteinase inhibitors (1-5), and also indirectly by the production of cytokines, such as interleukin $1(6,7)$ and tumor necrosis factor $(8,9)$, that induce ECM metalloproteinase gene expression in the resident cells of tissues.

Secreted metalloproteinases degrade the ECM and are active in tissue remodeling during morphogenesis, wound healing, inflammatory reactions, and a number of pathologic conditions including tumor invasion. To date, several enzymes of this class have been characterized: fibroblast $(10,11)$ and granulocyte $(12,13)$ collagenases, which degrade interstitial collagens; 72-kD type IV collagenase, which cleaves basement membrane collagen and also efficiently degrades several denatured collagen types or gelatins $(14,15)$; and stromelysin (16-18), an enzyme that degrades proteoglycans and other ECM components. These proteinases are closely related structurally $(11,15,17,18)$. Furthermore, comparison of the human fibroblast interstitial collagenase and rabbit interstitial collagenase genes with that of rat stromelysin has revealed a very similar genomic organization for these members of the metalloproteinase family $(19,20)$

Resident cells (particularly fibroblasts and endothelial cells) of tissues are usually considered the most important sources of secreted metalloproteinases. However, the production of interstitial collagenase by human monocytes and macrophages has recently been documented $(4,5,21,22)$. Furthermore, both human (23) and rabbit (24) macrophages have been reported to secrete a gelatinolytic enzyme of $92 \mathrm{kD}$, which also can readily cleave native types IV and V collagens. These findings suggest that human mononuclear phagocytes may have substantial capacity to degrade extracellular matrix via secreted metalloproteinases. To test this possibility, we have studied the production of four such enzymes by these cells. We have found that secretion of metalloproteinases is strongly regulated both by external signals and also by cellular differentiation; moreover, our results allow informative comparisons and contrasts to be made between mononuclear phagocytes and fibroblasts with regard to their arrays of secreted metalloproteinases.

\section{Methods}

Materials. Bovine serum albumin, phorbol 12-myristate 13-acetate (PMA), phenylmethylsulfonyl fluoride, EDTA, Triton X-100, concanavalin A (Con A), and protein-A Sepharose were obtained from Sigma Chemical Co. (St. Louis, MO). Lipopolysaccharide (LPS), derived from $E$. coli cell walls and purified by trichloroacetic acid extrac-

1. Abbreviations used in this paper: ECM, extracellular matrix; PAS, Protein A-Sepharose; TIMP, tissue inhibitor of metalloproteinases. 
tion, was also purchased from Sigma Chemical Co. (catalogue no. L-4255). All other chemicals were reagent grade.

Cells and cell culture conditions. Human alveolar macrophages were used as a prototypic macrophage source. They were harvested from healthy adult volunteer cigarette smokers (more than one pack per day) by saline bronchoalveolar lavage. More than $95 \%$ of the cells obtained were macrophages as determined by differential counting of Wright-stained cytocentrifuge preparations. The remaining cells were primarily lymphocytes; fibroblasts were not observed. The lavaged cells were washed three times in Hanks' balanced salt solution (HBSS) and plated in Linbro six-well cluster plates (Flow Laboratories, Inc., McLean, VA) at a concentration of $2 \times 10^{6}$ cells per well. The cells were incubated for $1 \mathrm{~h}$ at $37^{\circ} \mathrm{C}$ to allow attachment. The HBSS was then exchanged for culture medium (1:1 [vol/vol] Ham's F-12/Dulbecco's modified Eagle's medium [Ham's/DME]) and the cell cultures were maintained in humidified $95 \%$ air $/ 5 \% \mathrm{CO}_{2}(25)$.

Monocytes were isolated from the same volunteers who provided alveolar macrophages. The monocytes were separated from peripheral blood by Ficoll-Hypaque centrifugation (26), followed by elutriation centrifugation of the mononuclear cell layer as described previously (27). Differential counting of Wright-stained cytocentrifuge preparations revealed $>90 \%$ monocytes; the remainder of the cells were lymphocytes. Neither polymorphonuclear neutrophils nor platelets were observed in the preparations. Elutriated monocytes were washed once with HBSS, resuspended in Ham's/DME, and then plated in Linbro six-well cluster plates at $2 \times 10^{6}$ cells per well. After allowing the cells to adhere for $1 \mathrm{~h}$ at $37^{\circ} \mathrm{C}$, the cell layer was washed twice with fresh medium and the cultures were maintained at $37^{\circ} \mathrm{C}$ in humidified $95 \%$ air $/ 5 \% \mathrm{CO}_{2}$. Monocytes cultured long term for in vitro differentiation were incubated in Ham's/DME supplemented with $20 \%$ autologous human serum. The medium was changed every $3 \mathrm{~d}$ until day 7 when the cells were studied in comparison to freshly isolated monocytes and macrophages derived from the same individual.

To gain further insight into the effects of differentiation upon metalloproteinase expression, we used the human monocyte-like cell line U937. These cells were obtained from Dr. Hillel Koren, (Environmental Protection Agency, University of North Carolina, Chapel Hill, NC) and cultured in RPMI 1640 medium supplemented with $10 \%$ fetal bovine serum and $2 \mathrm{mM}$ L-glutamine as described previously (21). Control cells were studied for a period of $24 \mathrm{~h}$. Cells to be studied under differentiated conditions were exposed to $10^{-8} \mathrm{M}$ PMA for $24 \mathrm{~h}$, and were then subjected to experimental manipulation for the next $24 \mathrm{~h}$ of incubation.

Human skin fibroblasts, established as described previously (28), were cultured as confluent monolayers in DME containing $10 \%$ fetal bovine serum. Fibroblast cell number was determined by trypsinization and cell counting using a hemocytometer.

Collection of conditioned media. All media samples analyzed were conditioned in the presence of ${ }^{35} \mathrm{~S}$-labeled methionine for $24 \mathrm{~h}$. To determine the effects of LPS $(1 \mu \mathrm{g} / \mathrm{ml})$, PMA $\left(10^{-8} \mathrm{M}\right)$ and Con A (20 $\mu \mathrm{g} / \mathrm{ml}$ ), the cells were exposed to these agents for $24 \mathrm{~h}$ before labeling and then again during the study period. To begin the study period, culture medium was replaced with otherwise identical methionine-free medium containing $50 \mu \mathrm{Ci} / \mathrm{ml}$ of $\left[{ }^{35} \mathrm{~S}\right]$ methionine (Amersham Corp., Arlington Heights, IL) and the cells were metabolically labeled for the next $24 \mathrm{~h}$. After collection, the samples of conditioned medium containing the labeled proteins were stored at $-70^{\circ} \mathrm{C}$ until analysis

Immunologic assays. ELISA for human interstitial collagenase was performed on both fibroblast and macrophage-conditioned media samples as described previously (29). This assay is sensitive in the nanogram range and employs a polyclonal antibody that recognizes free collagenase with equal avidity to that of enzyme complexed with substrate or tissue inhibitor of metalloproteinases (TIMP).

Metabolic labeling and immunoprecipitation studies. Polyclonal antisera to human fibroblast collagenase (10), stromelysin (18), 72-kD type IV collagenase $(15)$, and TIMP $(28,30)$ were generated as described previously. Monospecific rabbit antisera was prepared against the 92-kD type IV collagenase purified from U937 cell-conditioned media and did not recognize 72-kD type IV collagenase (31).
The procedure for immunoprecipitation of the metalloproteinases and TIMP has been reported previously $(4,5,21)$. Processed samples were applied to $10 \%$ polyacrylamide slab gels and electrophoresis was performed as described by King and Laemmli (32). The $10 \%$ gels were equilibrated with $\mathrm{En}^{3} \mathrm{Hance}$ (New England Nuclear, Boston, MA) for $1.5 \mathrm{~h}$, rinsed in cold distilled water for $1 \mathrm{~h}$, and then dried under vacuum. The dried gels were exposed to Kodak XAR-5 X-Omat film (Eastman Kodak Co., Rochester, NY) at $-70^{\circ} \mathrm{C}$ (33).

A co-precipitating band of $M_{\mathrm{r}} 28 \mathrm{kD}$ was observed when U937 conditioned media was immunoprecipitated with antisera to the 92-kD type IV collagenase. Since it was suspected that this band might represent TIMP, the following procedure was employed to define its nature: on day 1 , antibody to TIMP was added to labeled conditioned media and incubated overnight. The pellet from day 2 (containing immunoprecipitated TIMP) was frozen at $-70^{\circ} \mathrm{C}$, while the supernatant fraction, after preclearing with Protein A-Sepharose (PAS), was incubated overnight with antibody to the $92-\mathrm{kD}$ enzyme. Before electrophoresis, the frozen pellets were thawed and subjected to the washing and releasing procedure described previously.

Substrate gel electrophoresis. Substrate gel electrophoresis (34) was performed on the immunoprecipitated samples of 72-kD type IV collagenase, using its previously reported capacity to efficiently degrade denatured type I collagen or gelatin (15). Aliquots of conditioned media from fibroblasts, monocytes, in vitro differentiated monocytes (monocyte-derived macrophages), and alveolar macrophages were subjected to the immunoprecipitation procedure for 72-kD type IV collagenase described above, except that the protein-antibody-PAS complex was released into sample buffer by heating at $37^{\circ} \mathrm{C}$ for 45 min. The samples were then applied without reduction to a $10 \%$ polyacrylamide slab gel impregnated with $1 \mathrm{mg} / \mathrm{ml}$ gelatin. Polyacrylamide gel electrophoresis was performed at $4^{\circ} \mathrm{C}$. After electrophoresis, the gel was incubated in $2.5 \%$ (vol/vol) Triton for $30 \mathrm{~min}$, and then overnight in $50 \mathrm{mM}$ Tris, $\mathrm{pH} 8.0$, containing $5 \mathrm{mM} \mathrm{CaCl}_{2}$, and $1 \mu \mathrm{M} \mathrm{ZnCl}_{2}$ at $37^{\circ} \mathrm{C}$. The gel was then stained with a solution of $0.125 \%$ Coomassie Blue. The immunoprecipitation procedure was employed since the activity of 72-kD type IV collagenase was more readily visualized without the simultaneous presence of the $92-\mathrm{kD}$ gelatinolytic enzyme in conditioned media.

Substrate gel electrophoresis was also performed on aliquots of conditioned media from monocytes, monocyte-derived macrophages, and alveolar macrophages to examine the production of $92-\mathrm{kD}$ type IV collagenase as a function of cellular differentiation. Samples were applied directly, without prior immunoprecipitation, since the 92-kD enzyme is the predominant secreted gelatinolytic proteinase.

\section{Results}

The effect of cellular differentiation on the secretion of ECMdegrading metalloproteinases was examined using blood monocytes, alveolar macrophages, and U937 cells. U937 cells were studied in their basal state and also after differentiation induced by phorbol esters. Alveolar macrophages were utilized as a prototypic, normal mononuclear phagocyte. In selected experiments, macrophage precursors (blood monocytes) from the same donor were examined, both immediately after harvesting and following in vitro differentiation into monocytederived macrophages.

92-kD type IV collagenase. The biosynthesis of $92-\mathrm{kD}$ type IV collagenase by human alveolar macrophages and its regulation by LPS and PMA are shown in Fig. 1. Secretion of this proteinase was stimulated three- to fourfold, as determined by densitometric scanning, after exposure of the cells to endotoxin or to phorbol ester. As expected, the increased enzyme production was mirrored by enhanced catalytic activity attributable to the $92-\mathrm{kD}$ species when conditioned media samples were applied to gelatin-impregnated polyacrylamide gels (zymograms; data not shown). 


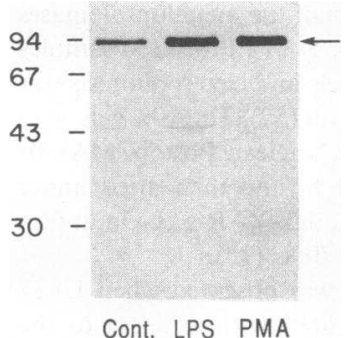

Figure 1. Regulation of $92-\mathrm{kD}$ type IV collagenase secretion in human alveolar macrophages. Macrophages were cultured in the presence of LPS $(1 \mu \mathrm{g} / \mathrm{ml})$ or PMA $\left(10^{-8} \mathrm{M}\right)$. The cells were then exposed to $\left[{ }^{35} \mathrm{~S}\right]-$ methionine, and the labeled secreted proteins were immunoprecipitated with antiserum specific for $92-\mathrm{kD}$ type IV collagenase. Note the 3.5and 3.8-fold stimulation of 92-kD enzyme synthesis by LPS and PMA, respectively, in comparison to untreated control cells, (Cont.), as determined by densitometric scanning of the autoradiograph. The co-precipitating bands at 28 and 45-50 kD have been identified as TIMP (Fig. $2 B$ ) and interstitial collagenase, respectively. Some cross-reactivity of the polyclonal 92-kD antisera with interstitial collagenase, a major related secretory product of such cells, is occasionally observed. This cross-reactivity is even more evident in Fig. $2 \mathrm{~A}$.

Expression of the $92-\mathrm{kD}$ gelatinolytic enzyme was dramatically stimulated during the phorbol-induced differentiation of U937 cells, as shown in Fig. $2 A$. This stimulation, as compared to rates of secretion in the basal state, was similar in magnitude to that previously observed for interstitial collagenase and TIMP after differentiation of U937 cells (21). Immunoprecipitation of the $92 \mathrm{kD}$ enzyme by specific antisera simultaneously co-precipitated substantial amounts of TIMP

A

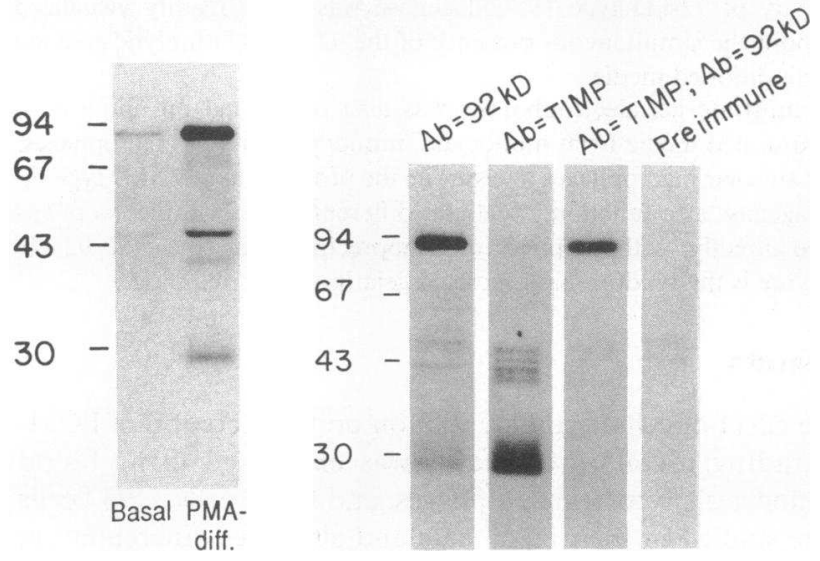

Figure 2. (A) Production of 92-kD type IV collagenase by U937 cells. U937 cells in the basal state or after differentiation with PMA $\left(10^{-8}\right.$ M) were exposed to $\left[{ }^{35}\right.$ S $]$ methionine, and the labeled secreted proteins immunoprecipitated with antiserum specific for 92-kD type IV collagenase. Note the marked induction of the $92-\mathrm{kD}$ enzyme with phorbol-induced differentiation. (B) Secretion of 92-kD type IV collagenase bound to TIMP. Labeled U937 cell-conditioned media was treated with 92-kD-specific antiserum, resulting in the co-precipitation of protein species of 92 and $28 \mathrm{kD}(A b=92 \mathrm{kD})$. Immunoprecipitation of the same conditioned media with TIMP antiserum identified the 28-kD band as TIMP $(A b=T I M P)$. Sequential immunoprecipitation of conditioned media with TIMP antiserum followed by 92-kD-specific antiserum (added to the supernatant) produced a homogeneous $92-\mathrm{kD}$ band with intensity of staining considerably reduced as compared to treatment with $92-\mathrm{kD}$ antiserum alone ( $A b$ $=T I M P ; A b=92 \mathrm{kD}$ ). Therefore, a significant fraction of $92-\mathrm{kD}$ enzyme appears to be secreted as a zymogen already complexed to TIMP.
(Fig. $2 B$ ). This co-precipitation was observed using both phorbol-differentiated U937 and LPS-stimulated macrophage conditioned media. These data suggest that TIMP forms a complex with the secreted $92 \mathrm{kD}$ zymogen species, in clear distinction to its inability to complex interstitial procollagenase $(35,36)$.

Expression of $92-\mathrm{kD}$ type IV collagenase was also studied as a function of the cellular differentiation of normal human mononuclear phagocytes. Conditioned media collected for 24 h from freshly harvested blood monocytes, monocytes differentiated in vitro for $7 \mathrm{~d}$ (monocyte-derived macrophages), and alveolar macrophages obtained from the same individual were subjected to gelatin substrate gel electrophoresis. As shown in Fig. 3, monocytes secreted detectable levels of the $92-\mathrm{kD}$ gelatinolytic enzyme, but production was substantially increased after in vitro maturation of the cells on a plastic surface or in vivo differentiation into alveolar macrophages.

72-kD type IV collagenase. Metabolic labeling of human alveolar macrophages and subsequent immunoprecipitation with specific antisera to $72-\mathrm{kD}$ type IV collagenase demonstrated the biosynthesis of a protein species migrating identically to human fibroblast $72 \mathrm{kD}$ type IV collagenase (Fig. 4). The previously reported $(14,15)$ gelatin-degrading activity of this enzyme was confirmed by substrate gel electrophoresis of both the immunoprecipitated material and the original conditioned media (data not shown). Macrophage secretion of 72-kD type IV collagenase was regulatable, but in manner clearly distinct from that previously observed with the $92-\mathrm{kD}$ gelatinolytic enzyme (Fig. 1) and interstitial collagenase (4, 37,

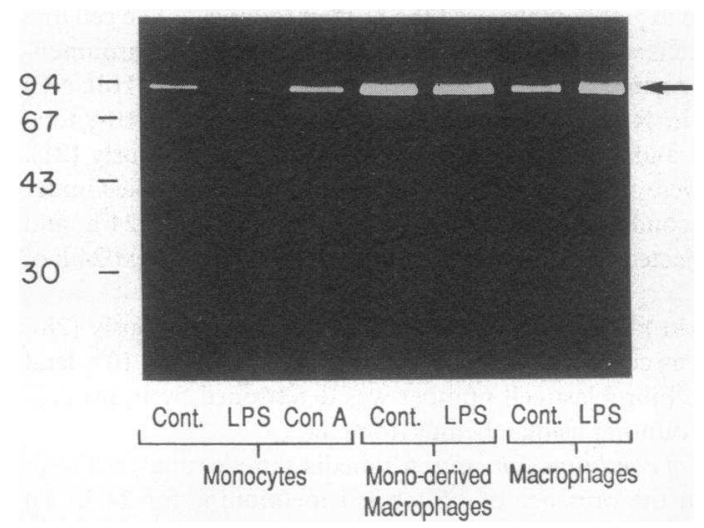

Figure 3. Production of 92-kD type IV collagenase by monocytes, monocyte-derived macrophages, and alveolar macrophages derived from the same individual. Conditioned media were collected for $24 \mathrm{~h}$ from untreated control (Cont., lane 1) and LPS (lane 2) and Con A (lane 3) -stimulated monocytes, from monocyte-derived macrophages (monocytes differentiated in vitro for $7 \mathrm{~d}$ before the 24-h collection) both constitutively (lane 4) and stimulated with LPS (lane 5 ), and from alveolar macrophages simultaneously obtained from the same donor under control (lane 6) and LPS-stimulated (lane 7) conditions. The media were applied to a gelatin-impregnated polyacrylamide slab gel as described under Methods. Note the enhanced production of the 92-kD enzyme that occurs with cellular differentiation of the mononuclear phagocytes in vitro or in vivo. The decreased release of the $92-\mathrm{kD}$ enzyme observed in lane 2 is most likely due to cytotoxicity by LPS to monocytes. This is suggested by concomitantly reduced values for total newly secreted proteins found in parallel culture wells that were labeled with $\left[{ }^{35} S\right]$ methionine and then subjected to cold trichloroacetic acid precipitation (counts per minute in lane $1=2,193$; lane $2=783$; lane $3=2,628$ ). 


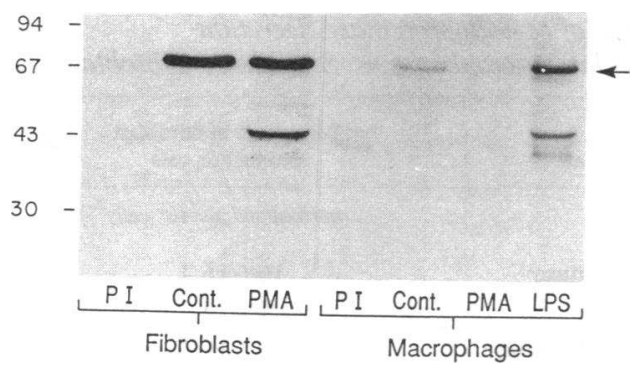

Figure 4. Regulation of 72-kD type IV collagenase production in human macrophages and fibroblasts. Human alveolar macrophages and human skin fibroblasts were cultured in the presence of $\left[{ }^{35} \mathrm{~S}\right]-$ methionine and the labeled secreted proteins immunoprecipitated with antiserum to $72-\mathrm{kD}$ type IV collagenase. The macrophages were exposed to PMA $\left(10^{-8} \mathrm{M}\right)$ or LPS $(1 \mu \mathrm{g} / \mathrm{ml})$; the fibroblasts were treated with PMA $\left(10^{-8} \mathrm{M}\right)$. Media treated with preimmune antiserum is designated as $P I$. Note the identity of the immunoprecipitated 72-kD species from both macrophages and fibroblasts. There is marked induction of 72-kD enzyme with LPS in macrophages; phorbol esters failed to upregulate production in either cell type. Again, the co-precipitated band at $45-50 \mathrm{kD}$ represents cross-reactivity with interstitial collagenase, a major secreted product of these cells.

38). Production of the 72-kD enzyme was stimulated by LPS, but the addition of PMA failed to enhance synthesis (Fig. 4). In contrast, differentiation of U937 cells induced by PMA was accompanied by significantly augmented $72-\mathrm{kD}$ type IV collagenase secretion as compared to cells in the basal state (Fig. 5). Since phorbol esters failed to stimulate the expression of 72-kD type IV collagenase in a fully mature cell, the human alveolar macrophage (Fig. 4), these data suggest that induction of this enzyme's biosynthesis in the U937 cells resulted from the capacity of such compounds to induce cellular differentiation, rather than a direct stimulation of transcription of this enzyme.

Since human monocytes have been reported to transiently express a metalloproteinase type IV collagenase of $\sim 70 \mathrm{kD}$ (39), with rapid disappearance of this catalytic activity noted as the cells differentiate into macrophages (39), we studied the production of the 72-kD type IV collagenase during the differentiation of normal human mononuclear phagocytes. Conditioned media were collected for a $24-\mathrm{h}$ period from freshly isolated peripheral blood monocytes, from monocytes differentiated in vitro on a plastic surface for $7 \mathrm{~d}$ (monocyte-derived macrophages), and from alveolar macrophages obtained from

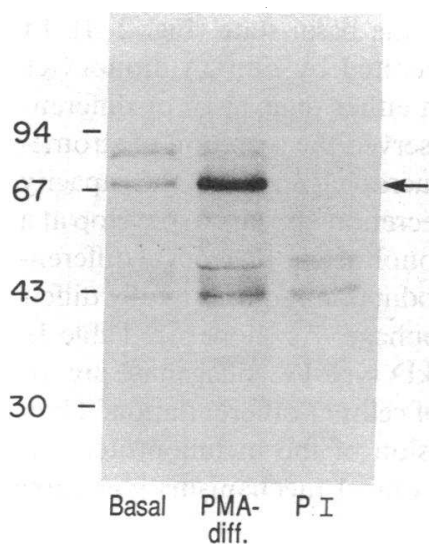

Figure 5. Production of 72-kD type IV collagenase by U937 cells. U937 cells in the basal state or after differentiation with PMA $\left(10^{-8} \mathrm{M}\right)$ were exposed to $\left[{ }^{35}\right.$ S $]$ methionine, followed by immunoprecipitation of the labeled secreted proteins with antiserum to $72-\mathrm{kD}$ type IV collagenase. Note the marked induction of $72-\mathrm{kD}$ type IV collagenase synthesis with phorbol-induced differentiation of the U937 cells. the same individual volunteers. After immunoprecipitation with antisera to 72-kD type IV collagenase, the samples were subjected to gelatin substrate gel electrophoresis (Fig. 6). Metabolically labeled conditioned media samples were also collected and processed by immunoprecipitation and autoradiography (data not shown). Using both procedures, freshly isolated human monocytes failed to produce catalytically or immunologically detectable $72-\mathrm{kD}$ type IV collagenase. In contrast, secretion of this enzyme was readily observed after in vitro differentiation of monocytes on plastic or in macrophages differentiated in vivo (Fig. 6). These results, obtained from three different volunteers, are very consistent with the data shown for U937 cells in Fig. 5, and suggest that the capacity for $72-\mathrm{kD}$ type IV collagenase expression actually increases with the cellular differentiation of human mononuclear phagocytes.

Stromelysin. Labeled conditioned media from human alveolar macrophages and skin fibroblasts were subjected to immunoprecipitation using antiserum specific for human stromelysin. As shown in Fig. 7, macrophages secreted a doublet species of $60,57 \mathrm{kD}$ that exhibited identical electrophoretic migration to the protein immunoprecipitated from fibroblasts. However, stromelysin production could be demonstrated from human macrophages only after stimulation with LPS (Fig. 7). Control cells and cells exposed to phorbol esters did not release detectable amounts of this enzyme. Furthermore, U937 cells failed to produce stromelysin under any tested condition, including cells cultured in the basal state, cells differentiated with phorbol ester compounds, and even after the addition of LPS to fully phorbol-differentiated cells. These results contrast with the marked stimulation of $92-\mathrm{kD}$ type IV collagenase (Fig. 2 $A$ ), 72-kD type IV collagenase (Fig. 5), and interstitial collagenase (21) that accompanies the differentiation of U937 cells.

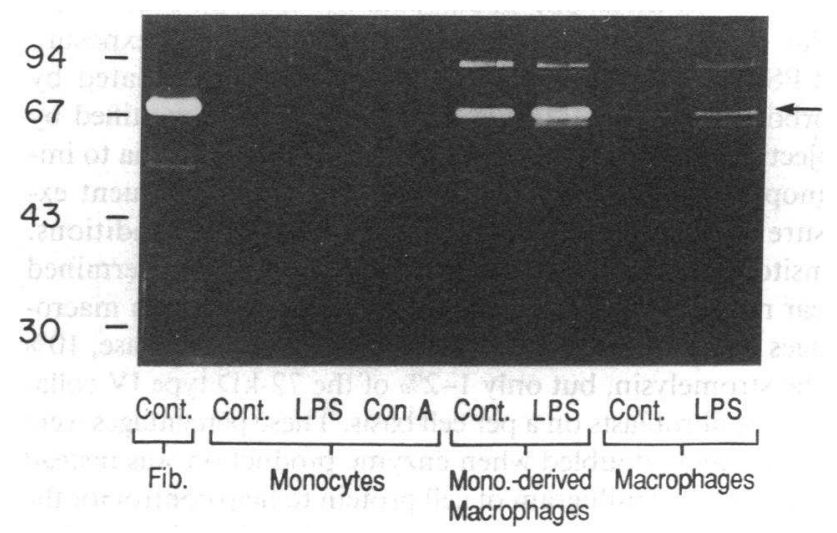

Figure 6. Production of $72-\mathrm{kD}$ type IV collagenase by monocytes, monocyte-derived macrophages, and alveolar macrophages derived from the same individual. Conditioned media were collected for $24 \mathrm{~h}$ from untreated (lane 2), LPS (lane 3), and Con A (lane 4 ) stimulated monocytes, from monocyte-derived macrophages (monocytes differentiated in vitro for $7 \mathrm{~d}$ before the 24 -h collection) both constitutively (lane 5) and stimulated with LPS (lane 6), and from alveolar macrophages simultaneously obtained from the same donor under control (lane 7) and LPS-stimulated (lane 8) conditions. Fibroblastconditioned media is shown in lane 1 . The secreted proteins were immunoprecipitated with antiserum to 72-kD type IV collagenase, and the bound material applied to a gelatin-impregnated polyacrylamide slab gel as described under Methods. Gelatinolytic activity at $72 \mathrm{kD}$ was never observed from monocyte samples, even when conditioned media were collected for a 48 -h period after initial plating. 


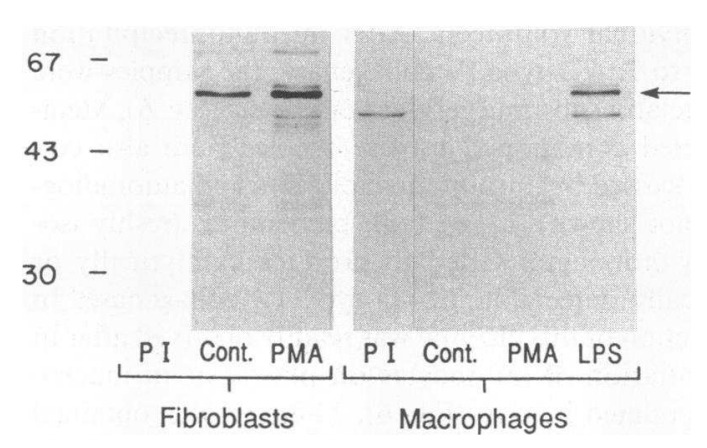

Figure 7. Regulation of stromelysin production in human macrophages and fibroblasts. Human alveolar macrophages and human skin fibroblasts were cultured in the presence of $\left[{ }^{35} \mathrm{~S}\right] \mathrm{methionine}$ and the labeled secreted proteins immunoprecipitated with antiserum to stromelysin. The fibroblasts were exposed to PMA $\left(10^{-8} \mathrm{M}\right)$ and the macrophages to PMA $\left(10^{-8} \mathrm{M}\right)$ or LPS $(1 \mu \mathrm{g} / \mathrm{ml})$. Conditioned media treated with preimmune antiserum is designated as PI. Note the identity of the immunoprecipitated stromelysin bands from both macrophages and fibroblasts. PMA induced stromelysin production in fibroblasts, but not in macrophages. LPS caused a marked stimulation of macrophage stromelysin biosynthesis.

Macrophage and fibroblast metalloproteinase production. To gain further insight into the potential of mononuclear phagocytes to directly modulate connective tissue turnover, we quantified the amounts of each metalloproteinase secreted by metabolically labeled macrophages and fibroblasts. In order to determine whether metabolic pools of $\left[{ }^{35} \mathrm{~S}\right]$ methionine used for pulsing were equally available to both cell types, the amount of radioactivity incorporated into interstitial collagenase protein was compared to levels of steady-state secreted collagenase as measured by ELISA. The results of this measurement revealed that both cell types have similar specific activity of ${ }^{35} \mathrm{~S}$ metabolic pools (data not shown). Human alveolar macrophages were maximally stimulated by exposure to LPS; human fibroblasts were maximally stimulated by phorbol ester (PMA). Enzyme production was quantified by subjecting serial dilutions of labeled conditioned media to immunoprecipitation with specific antisera and subsequent exposure of the autoradiographs under identical conditions. Densitometry was then performed in a previously determined linear range of scanning. As shown in Table I, human macrophages secreted $\sim 15-20 \%$ of the interstitial collagenase, $10 \%$ of the stromelysin, but only $1-2 \%$ of the $72-\mathrm{kD}$ type IV collagenase as fibroblasts on a per cell basis. These percentages were approximately doubled when enzyme production was instead normalized per milligram of cell protein to help control for the larger cell size of fibroblasts. As mentioned earlier, and as reported by others $(23,24)$, production of the $92-\mathrm{kD}$ type IV collagenase was restricted to human mononuclear phagocytes.

\section{Discussion}

We have found that human mononuclear phagocytes secrete a spectrum of neutral metalloproteinases, including 72-kD type IV collagenase, stromelysin, and interstitial collagenase (4), which are identical to those of human fibroblasts. Furthermore, these cells also secrete $92-\mathrm{kD}$ type IV collagenase (23, $24)$, which is not produced by human fibroblasts.

Our data clearly indicate that stage of mononuclear phagocyte differentiation has profound effects upon capacity for metalloproteinase expression. Cellular differentiation appears
Table I. Comparison of Metalloproteinase Secretion by Stimulated Alveolar Macrophages vs. Stimulated Fibroblasts

\begin{tabular}{lc}
\hline \multicolumn{1}{c}{ Metalloproteinase } & $\begin{array}{c}\text { Percentage of fibroblast } \\
\text { production rate }\end{array}$ \\
\hline Interstitial collagenase & normalized per $10^{6}$ cells \\
Stromelysin & $16.6 \pm 6.1$ \\
72-kD type IV collagenase & $9.2 \pm 3.2$ \\
& $1.5 \pm 0.6$ \\
Interstitial collagenase & normalized per $m g$ cell protein \\
Stromelysin & $37.1 \pm 13.7$ \\
72-kD type IV collagenase & $20.6 \pm 7.2$ \\
\end{tabular}

Production of the various metalloproteinases was determined in human alveolar macrophages versus human skin fibroblasts. Macrophages were maximally stimulated by exposure to LPS $(1 \mu \mathrm{g} / \mathrm{ml})$. Confluent fibroblasts were maximally stimulated by $10^{-8} \mathrm{M}$ PMA. Synthesis of stromelysin and 72-kD type IV collagenase were quantified by immunoprecipitation of serial dilutions of labeled conditioned media followed by densitometric scanning of the autoradiographs. For each enzyme studied, immunoprecipitated material from one individual's macrophages and one cell line of fibroblasts were run on the same gel and exposed under identical conditions. Densitometry was performed in a previously determined linear range of scanning. The data shown for interstitial collagenase were derived from a previous report (25). Mean values \pm standard deviation are presented as a percentage of fibroblast production rates and were determined for three subjects' macrophages and three lines of human fibroblasts. Data are normalized both to cell number and to cell protein (40) as detailed under Methods

to correlate with production of greater quantities, and a wider spectrum, of enzymes (Table II). Thus, the biosynthesis of 92-kD type IV collagenase, 72-kD type IV collagenase, and interstitial collagenase (21) were all dramatically increased in U937 cells after phorbol-induced differentiation. Furthermore, production of the $92-$ and $72-\mathrm{kD}$ type IV collagenases increased markedly and became subject to regulatory signals as monocytes were differentiated into macrophages in vitro or in vivo (Figs. 1, 3, and 6).

The capacity for expression of each given metalloproteinase appears to be acquired at separate and particular times during development, rather than coordinately as a group. As shown in Table II, the $92-\mathrm{kD}$ type IV collagenase is a prominent secretory product of both blood monocytes and alveolar macrophages; its secretion can be upregulated by LPS and PMA (Fig. 1). Furthermore, small amounts of this enzyme are secreted even by U937 cells in the basal state (Fig. $2 A$ ). In contrast, stromelysin is not secreted by human monocytes (Table II), nor by U937 cells in either their basal or differentiated state. In fact, we have observed the secretion of stromelysin only in LPS-stimulated macrophages. Thus, the capacity for 92-kD type IV collagenase secretion appears to develop at a comparatively early stage of mononuclear phagocyte differentiation, whereas stromelysin production requires a fully differentiated and stimulated macrophage. As shown in Table II, interstitial collagenase and 72-kD type IV collagenase are expressed at intermediate stages of cellular differentiation. Thus, the distinct patterns of expression of the metalloproteinases provide evidence for varying control mechanisms governing their synthesis. 
Table II. Effects of Cellular Differentiation on Metalloproteinase Expression

\begin{tabular}{|c|c|c|c|c|c|c|}
\hline \multirow[b]{2}{*}{ Enzyme } & \multicolumn{2}{|c|}{ Monocytes } & \multicolumn{2}{|c|}{$\begin{array}{c}\text { Alveolar } \\
\text { macrophages }\end{array}$} & \multicolumn{2}{|c|}{ U937 cells } \\
\hline & Basal & Stimulated & Basal & Stimulated & Basal & Differentiated \\
\hline $\begin{array}{c}\text { 92-kD type IV } \\
\text { collagenase }\end{array}$ & + & + & + & ++ & $(+)$ & ++ \\
\hline $\begin{array}{l}\text { Interstitial } \\
\text { collagenase }\end{array}$ & $(+)$ & $(+)$ & $(+)$ & ++ & - & ++ \\
\hline $\begin{array}{c}\text { 72-kD type IV } \\
\text { collagenase }\end{array}$ & - & - & $(+)$ & + & $(+)$ & + \\
\hline Stromelysin & - & - & - & + & - & - \\
\hline
\end{tabular}

Metalloproteinase production was determined in basal and Con A-stimulated monocytes, basal and LPS-stimulated alveolar macrophages, and basal and phorbol-differentiated U937 cells as presented in the text. The parentheses indicate the presence of only barely detectable levels of enzyme production. The data for interstitial collagenase are derived from two previous reports $(21,25)$. Note that the expression of $92-\mathrm{kD}$ type IV collagenase requires a comparatively less differentiated mononuclear phagocyte phenotype, whereas stromelysin is produced only by the fully differentiated and stimulated alveolar macrophage.

Our results contrast with those in a recent study (39) that described type IV collagenase activity from freshly isolated human monocytes whose secretion diminished rapidly over 48 $\mathrm{h}$ in culture. This activity was attributed to $\mathrm{a} \sim 70-\mathrm{kD}$ type IV collagenase which was observed to be secreted by endotoxinstimulated macrophages. Secretion of this enzyme was hypothesized to underlie the mechanism whereby peripheral blood monocytes traverse basement membranes to exit from the circulation. Our results (Fig. 6) demonstrate that freshly harvested human monocytes placed in culture for $24 \mathrm{~h}$ failed to secrete 72-kD type IV collagenase detectable either by immunologic criteria or by functional catalytic activity. Rather, expression of this enzyme was observed from monocytes only after in vitro maturation, and from in vivo differentiated human macrophages, both basally and after stimulation with LPS. Furthermore, secretion of the 92-kD gelatinolytic enzyme, which has very recently been shown to have type IV collagenolytic activity (31), also increased with the acquisition of a more differentiated phenotype as monocytes differentiated into macrophages in vitro or in vivo. These observations therefore raise the question as to whether peripheral blood monocytes secrete or even require a metalloenzyme with type IV collagenase activity for their transit from the peripheral circulation. Monocytes do contain a readily-secreted serine proteinase, human leukocyte elastase (1), that may provide the capacity to degrade type IV collagen $(41,42)$ and permit monocytes to traverse basement membranes.

LPS induced a marked up-regulation in the biosynthesis of every secreted macrophage metalloproteinase examined: 92-kD type IV collagenase, 72-kD type IV collagenase, stromelysin, and interstitial collagenase. While LPS has also been reported to stimulate TIMP secretion (4), this effect is comparatively modest, suggesting that the presence of endotoxin in vivo shifts human macrophages towards a matrix-degradative phenotype.

In contrast to LPS, PMA upregulated the biosynthesis of 92-kD type IV collagenase and interstitial collagenase (4), but failed to stimulate $72-\mathrm{kD}$ type IV collagenase or stromelysin. Thus, it appears that biologic control mechanisms exist to regulate the expression of human macrophage metalloproteinases both individually (e.g., phorbol esters) and also coordi- nately as a group (e.g., LPS). Furthermore, one may speculate that the $72-\mathrm{kD}$ type IV collagenase cannot be regulated by PMA owing to the absence of a phorbol-responsive element in the gene's promoter region (43), since phorbol esters similarly fail to augment the synthesis of this enzyme in fibroblasts ([15]; Fig. 4). It is noteworthy that treatment with PMA likewise failed to stimulate stromelysin production in macrophages. In contrast, the expression of stromelysin is markedly upregulated by phorbol esters in human fibroblasts ([18]; Fig. 7), indicating cell type-specific control mechanisms for the secretion of this enzyme.

The proteinases studied in this report confer a considerable potential for matrix degradation on human mononuclear phagocytes which produce them. At later stages of differentiation, and particularly when their phenotype is shifted by extracellular signals such as LPS, these cells secrete enzymes capable of degrading at least the following matrix constituents: native collagen types I, II, III, IV, V, VII, and X; denatured collagens; laminin; fibronectin; and proteoglycans. Although macrophages have the capacity to degrade ECM components by the secretion of an array of metalloproteinases, their precise role in the mediation of destructive pathologic processes must be the subject of considerable future research. It is of interest, however, that the spectrum of metalloproteinases secreted by macrophages differs both qualitatively and quantitatively from that of fibroblasts. These differences may reflect biologically important contrasts in ECM remodeling mediated by these cells.

\section{Acknowledgments}

The authors thank Ms. Lou Anne Davidson for assistance in the preparation of this manuscript.

This work was supported by U.S. Public Health Service grants AR-35805, AR-39427, AR-12129, and AR-07284, and National Heart, Lung, and Blood Institute grant HL-29594 from the National Institutes of Health. Support was also provided by The Council for Tobacco Research, USA, Inc. (grant no. 1724A), and by the Monsanto Company/Washington University Research Agreement.

\section{References}

1. Campbell, E. J., E. K. Silverman, and M. A. Campbell. 1989. Elastase and cathepsin $G$ of human monocytes: quantification of cellular content, release in response to stimuli, and heterogeneity in elastase-mediated proteolytic activity. J. Immunol. 143:2961-2968.

2. Sandhaus, R. A., K. M. McCarthy, R. A. Musson, and P. M. Henson. 1983. Elastolytic proteinases of the human macrophage. Chest. 83(Suppl.):60-62.

3. Chapman, H. A., O. L. Stone, and Z. Vavrin. 1984. Degradation of fibrin and elastin by intact human alveolar macrophages in vitro: characterization of a plasminogen activator and its role in matrix degradation. J. Clin. Invest. 73:806-815.

4. Welgus, H. G., E. J. Campbell, Z. Bar-Shavit, R. M. Senior, and S. L. Teitelbaum. 1985. Human alveolar macrophages produce a fibroblast-like collagenase and collagenase inhibitor. J. Clin. Invest. 76:219-224.

5. Campbell, E. J., J. D. Cury, C. J. Lazarus, and H. G. Welgus. 1987. Monocyte procollagenase and tissue inhibitor of metalloproteinases: identification, characterization, and regulation of secretion. $J$. Biol. Chem. 262:15862-15868.

6. Dayer, J.-M., J. Breard, L. Chess, and S. M. Krane. 1979. Participation of monocyte-macrophages and lymphocytes in the production of a factor that stimulates collagenase and prostaglandin release by rheumatoid synovium. J. Clin. Invest. 64:1386-1392.

7. Dayer, J.-M., B. Derochem, B. Burrus, S. Demczuk, and C. A. Dinarell. 1986. Human recombinant interleukin-1 stimulates colla- 
genase and prostaglandin E-2 production by human synovial cells. $J$. Clin. Invest. 77:645-648.

8. Dayer, J.-M., B. Beutler, and A. Cerami. 1985. Cachectin tumor necrosis factor stimulates collagenase and prostaglandin-E-2 production by human synovial cells and dermal fibroblasts. J. Exp. Med. 162:2163-2168.

9. Seckinger, P., S. Isaaz, and J.-M. Dayer. 1988. A human inhibitor of tumor necrosis factor alpha. J. Exp. Med. 167:1511-1516.

10. Stricklin, G. P., E. A. Bauer, J. J. Jeffrey, and A. Z. Eisen. 1977. Human skin collagenase: isolation of precursor and active forms from both fibroblast and organ cultures. Biochemistry. 16:1607-1615.

11. Goldberg, G. I., S. M. Wilhelm, A. Kroneberger, E. A. Bauer, G. A. Grant, and A. Z. Eisen. 1986. Human fibroblast collagenase: complete primary structure and homology to an oncogene transformation-induced rat protein. J. Biol. Chem. 261:6600-6605.

12. Hasty, K. A., M. S. Hibbs, A. H. Kang, and C. L. Mainardi. 1984. Heterogeneity among human collagenases demonstrated by monoclonal antibody that selectively recognizes and inhibits human neutrophil collagenase. J. Exp. Med. 159:1455-1463.

13. Hasty, K. A., M. S. Hibbs, A. H. Kang, and C. L. Mainardi. 1986. Secreted forms of human neutrophil collagenase. J. Biol. Chem. 261:5645-5650.

14. Salo, T., T. Turpeenniemi-Hujanen, and K. Tryggvason. 1985. Tumor-promoting phorbol esters and cell proliferation stimulate secretion of basement membrane (type IV) collagen-degrading metalloproteinase by human fibroblasts. J. Biol. Chem. 260:8526-8531.

15. Collier, I. E., S. M. Wilhelm, A. Z. Eisen, B. L. Marmer, G. A. Grant, J. L. Seltzer, A. M. Kronberger, C. He, E. A. Bauer, and G. I. Goldberg. 1988. Human bronchial epithelial cells respond to transformation with $\mathrm{H}$-ras oncogene by secretion of a single metalloprotease capable of degrading basement membrane collagen. J. Biol. Chem. 263:6579-6587.

16. Chin, J. R., G. Murphy, and Z. Werb. 1985. Stromelysin, a connective tissue-degrading metalloendopeptidase secreted by stimulated rabbit synovial fibroblasts in parallel with collagenase. J. Biol. Chem. 260:12367-12376.

17. Whitham, S. E., G. Murphy, P. Angel, H.-J. Rahmsdorf, B. J. Smith, A. Lyons, T. J. Harris, J. J. Reynolds, P. Herrlich, and A. J. Docherty. 1986. Comparison of human stromelysin and collagenase by cloning and sequence analysis. Biochem. J. 240:913-916.

18. Wilhelm, S. M., I. E. Collier, A. M. Kronberger, A. Z. Eisen, B. L. Marmer, G. A. Grant, E. A. Bauer, and G. I. Goldberg. 1987. Human skin fibroblast stromelysin: Structure, glycosylation, substrate specificity, and differential expression in normal and tumorigenic cells. Proc. Natl. Acad. Sci. USA. 84:6725-6729.

19. Fini, M. E., I. M. Plucinska, A. S. Meyer, R. H. Gross, and C. E. Brinckerhoff. 1987. A gene for rabbit synovial cell collagenase: member of a family of metalloproteinases that degrade the connective tissue matrix. Biochemistry. 26:6156-6165.

20. Collier, I. E., J. Smith, A. Kronberger, E. A. Bauer, S. M. Wilhelm, A. Z. Eisen, and G. I. Goldberg. 1988. The structure of the human skin fibroblast collagenase gene. J. Biol. Chem. 263:1071110713.

21. Welgus, H. G., N. L. Connolly, and R. M. Senior. 1986. TPAdifferentiated U937 cells express a macrophage-like profile of neutral proteinases: high levels of secreted collagenase and collagenase inhibitor accompany low levels of intracellular elastase and cathespin G. $J$. Clin. Invest. 77:1675-1681.

22. Senior, R. M., N. L. Connolly, E. J. Campbell, and H. G. Welgus. 1986. Human mononuclear phagocytes produce different proteinases at different stages of differentiation: observations with TPA-differentiated U-937 cells. In Pulmonary Emphysema and Proteolysis. Academic Press, Inc., New York. 219-226.

23. Hibbs, M. S., J. R. Hoidal, and A. H. Kang. 1987. Expression of a metalloproteinase that degrades native type $\mathrm{V}$ collagen and denatured collagens by cultured human alveolar macrophages. J. Clin. In vest. 80:1644-1650.

24. Mainardi, C. L., M. S. Hibbs, K. A. Hasty, and J. M. Seyer. 1984. Purification of type $\mathrm{V}$ collagen degrading metalloproteinase from rabbit alveolar macrophages. Collagen Relat. Res. 4:479-492.

25. Cury, J. D., E. J. Campbell, C. J. Lazarus, R. J. Albin, and H. G. Welgus. 1988. Selective upregulation of human alveolar macrophage collagenase production by lipopolysaccharide and comparison to collagenase production by fibroblasts. J. Immunol. 141:4306-4312.

26. Boyum, A. 1963. Isolation of mononuclear cells and granulocytes from human blood: isolation of mononuclear cells by one centrifugation and of granulocytes by combining centrifugation and sedimentation at 1 g. Scand. J. Clin. Lab. Invest. 21(Suppl. 97):77-89.

27. Sanderson, R. J., F. T. Shepperdson, A. E. Vatter, and D. W. Talmage. 1977. Isolation and enumeration of peripheral blood monocytes. J. Immunol. 118:1409-1414.

28. Stricklin, G. P., and H. G. Welgus. 1983. Human skin fibroblast collagenase inhibitor: purification and biochemical characterization. J. Biol. Chem. 258:12252-12258.

29. Cooper, T. W., E. A. Bauer, and A. Z. Eisen. 1982. Enzymelinked immunosorbent assay for human skin collagenase. Collagen Relat. Res. 3:205-216.

30. Welgus, H. G., and G. P. Stricklin. 1983. Human skin fibroblast collagenase inhibitor: comparative studies in human connective tissues, serum, and amniotic fluid. J. Biol. Chem. 258:12259-12264.

31. Wilhelm, S. M., I. Collier, B. L. Marmer, A. Z. Eisen, G. A. Grant, and G. I. Goldberg. 1989. SV-40-transformed human lung fibroblasts secrete a 92-kDa type IV collagenase which is identical to that secreted by normal human macrophages. J. Biol. Chem. 264:17213-17221.

32. King, J., and U. K. Laemmli. 1971. Polypeptides of the tail fibres of bacteriophage T4. J. Mol. Biol. 62:465-477.

33. Lasky, R. A., and A. D. Mills. 1975. Quantitative film detection of ${ }^{3} \mathrm{H}$ and ${ }^{14} \mathrm{C}$ in polyacrylamide gels by fluorography. Eur. J. Biochem. $56: 335-341$

34. Birkedal-Hansen, H., and R. E. Taylor. 1982. Detergent-activation of latent collagenase and resolution of its component molecules. Biochem. Biophys. Res. Commun. 107:1173-1178.

35. Cawston, T. E., G. Murphy, E. Mercer, W. A. Galloway, B. L. Hazelman, and J. J. Reynolds. 1983. The interaction of purified rabbit bone collagenase with purified rabbit bone metalloproteinase inhibitor. Biochem. J. 211:313-318.

36. Welgus, H. G., J. J. Jeffrey, A. Z. Eisen, W. T. Roswit, and G. P. Stricklin. 1985. Human skin fibroblast collagenase: interaction with collagen and collagenase inhibitor. Collagen Relat. Res. 5:167-179.

37. Brinckerhoff, C. E., N. H. Gross, H. Nagase, L. Sheldon, R. C. Jackson, and E. D. Harris, Jr. 1982. Increased level of translatable collagenase mRNA in rabbit synovial fibroblasts treated with phorbol myristate acetate or crystals of monosodium urate monohydrate. Biochemistry. 21:2674-2679.

38. Wilhelm, S. M., A. Z. Eisen, M. Teter, S. D. Clark, A. Kronberger, and G. I. Goldberg. 1986. Human fibroblast collagenase: glycosylation and tissue-specific levels of enzyme synthesis. Proc. Natl. Acad. Sci. USA. 83:3756-3760.

39. Barbisa, S., M. Ballin, D. Daga-Gordini, G. Fastelli, M. Naturale, A. Negro, G. Semenzato, and L. Liotta. 1986. Transient expression of type IV collagenolytic metalloproteinase by human mononuclear phagocytes. J. Biol. Chem. 261:2369-2375.

40. Sedmak, J. J., and S. E. Grossberg. 1977. A rapid, sensitive, and versatile assay for protein using coomassie brilliant blue G250. Anal. Biochem. 79:544-548.

41. Pipoly, D. J., and E. C. Crouch. 1987. Degradation of native type IV procollagen by human neutrophil elastase: implications for leukocyte-mediated degradation of basement membranes. Biochemistry. 26:5748-5754.

42. Mainardi, C. L., S. N. Dixit, and A. H. Kang. 1980. Degradation of type IV (basement membrane) collagen by a proteinase isolated from human polymorphonuclear leukocyte granules. J. Biol. Chem. 255:5435-5441.

43. Angel, P., M. Imagawa, R. Chiu, B. Stein, R. J. Imbra, Rahmsdorf, C. Jonat, P. Herrlich, and M. Karin. 1987. Phorbol ester-inducible genes contain a common cis element recognized by TPA-modulated trans-acting factor. Cell. 49:729-739. 